\title{
Clinical features and laboratory findings in children hospitalized with acute Epstein-Barr virus infection: a cross- sectional study in a tertiary care hospital
}

\author{
İlknur Çağlar ${ }^{1}, \quad$ Sevgi Topal ${ }^{2}$, Melike Çokboz ${ }^{1}$, Mine Düzgöl ${ }^{1}$, Ahu Kara ${ }^{1}$, \\ Süleyman Nuri Bayram¹ ${ }^{1}$, Hurşit Apa ${ }^{3}$, İlker Devrim ${ }^{1}$ \\ Departments of ${ }^{1}$ Pediatric Infectious Diseases, ${ }^{2}$ Pediatric Critical Care and ${ }^{3}$ Pediatric Emergency Care, Dr. Behçet Uz \\ Children's Hospital, Izmir, Turkey.E-mail:dr_ilknur@yahoo.com
}

Received: 16th November 2017, Accepted: 24th May 2018

SUMMARY: Çağlar İ, Topal S, Çokboz M, Düzgöl M, Kara A, Bayram SN, Apa $\mathrm{H}$, Devrim I. Clinical features and laboratory findings in children hospitalized with acute Epstein-Barr virus infection: a cross-sectional study in a tertiary care hospital. Turk J Pediatr 2019; 61: 368-373.

\begin{abstract}
Epstein-Barr virus (EBV) is widespread all over the world. It causes infectious mononucleosis (IM) mostly in adolescents and adults. Although IM is considered to be rare in younger children and infants, acute EBV infection may have various manifestations in this age group. We aimed to describe the clinical features and laboratory findings of children hospitalized with acute EBV infection. All children hospitalized at Dr. Behçet Uz Children's Hospital, between January 2010 and January 2017, who tested positive by presence of EBV-specific antibodies and had the diagnosis of acute EBV infection, were included $(n=66)$. Thirty four of the patients $(51.5 \%)$ were under 6 years of age, and $23(34.8 \%)$ children were below 3 years of age. The most common physical finding was fever $(92.4 \%)$ followed by cervical lymphadenopathy and tonsillopharyngitis. Leukocytosis $(65.1 \%)$ and lymphocytosis $(42.4 \%)$ were the most common laboratory findings. Reactive and atypical lymphocytes were present in $77.2 \%$ of the patients. Fifty-three $(80.3 \%)$ of the patients had a doctor visit before hospitalization, and the ratio of patients using antibiotics was $77.3 \%$. Skin rash was observed in $14(27.4 \%)$ of the patients who used antibiotic treatment and in $2(13.3 \%)$ of the patients who did not $(p>0.05)$. EBV infection resulting in admission to hospital is common in younger children, even in pre-school period. Serological tests for EBV specific antibody responses and peripheral blood smear evaluation are important diagnostic tools. In addition, rapid streptococcal antigen test and throat culture should be performed in patients presenting with tonsillopharyngitis in order to exclude Group A beta-hemolytic streptococci and reduce unnecessary antibiotic consumption.
\end{abstract}

Key words: Epstein-Barr virus (EBV), infectious mononucleosis, children, tonsillopharyngitis.

Epstein-Barr virus (EBV) is a double-stranded DNA virus, a member of the Herpesviridae family and widespread all over the world, infecting $90-95 \%$ of the adult population. ${ }^{1}$ In contrast, the seroprevalence ratio of EBV among children is lower, varying from $20 \%$ to $80 \%$ and it is inversely related to age and the development level of the countries. ${ }^{2}$ Transmission of the virus requires intimate contact and sharing saliva; the incubation period is $4-8$ weeks. ${ }^{3,4}$ Acute symptomatic infection of EBV is called infectious mononucleosis (IM) and is mostly seen in adolescents and adults. ${ }^{5}$ In younger children and infants, EBV infection is usually asymptomatic or has a mild clinical course presenting with diarrhea, otitis media or upper respiratory tract infection and IM is rarely seen in this age group. ${ }^{6} \mathrm{EBV}$ infection may 
cause various acute and chronic complications ranging from mild complications such as fatigue or allergy to life threatening conditions including splenic rupture, acute liver failure, hemophagocytic lymphohistiocytosis (HLH) and malignancy. ${ }^{7}$ With its wide spectrum of clinical manifestations, EBV is an important infectious agent in children.

The aim of the present study was to describe the clinical features and laboratory findings of children hospitalized with acute EBV infection diagnosis in a pediatric infectious disease ward during a 7 -years period.

\section{Material and Methods}

Children who were hospitalized at the pediatric infectious disease ward of Dr. Behçet Uz Children's Hospital, with the diagnosis of acute EBV infection, between 1 January 2010 - 1 January 2017 were included in this cross-sectional study. Demographic variables, medical history, clinical features and laboratory findings were collected from medical records and registered in a form. All serum samples from the patients were tested using a chemiluminescent microparticle immunoassay (CMIA) system, Architect EBV Antibody Panel (Abbott, Wiesbaden, Germany). The test results were interpreted according to Table I. Patients were considered to have acute/ primary EBV infection in the presence of EBV viral capsid antigen (VCA) IgM positivity while EBV nuclear antigen (EBNA) IgG was negative. Individuals with missing medical records or positive EBNA IgG result were not included in the study. Laboratory findings of the patients were shown in Table II.

This study was a retrospective chart review and no intervention was planned. Hence keeping in accordance of confidentiality protocol of the institute, no additional informed consent was obtained from the patient after approval from the institutional ethical committee.

\section{Statistics}

Statistical analysis was performed using SPSS, version 15.0 (IBM SPSS, Chicago, Illinois). Quantitative data were shown as the mean \pm standard deviation (SD) or the median with interquartile ranges (Q1-Q3). Qualitative variables were expressed as absolute and relative frequencies. Chi-square, with Fisher's exact correction where required for discrete variables, and Student's t-test for parametric and Wilcoxon rank sum test for non-parametric continuous variables were used. Significance was set at $\mathrm{p}<0.05$.

\section{Results}

Seventy-one patients who were diagnosed with EBV infection and admitted to the pediatric infectious diseases ward of Dr. Behçet Uz Children's Hospital between January 2010 and January 2017 were enrolled. Sixty-six patients with complete medical data were included in the study. Thirty-five of the patients $(53.0 \%)$ were male and 31 (47.0\%) were female. The median age of the children was 5 years 9 months (minimum 1 year - maximum 17 years). Thirty four of the patients $(51.5 \%)$

Table I. Interpretation of Epstein-Barr Virus (EBV) Specific Serology.

\begin{tabular}{cccl}
\hline & Test result & & \multicolumn{1}{c}{ Clinical interpretation } \\
\cline { 1 - 3 } VCA IgM & VCA IgG & EBNA IgG & \multicolumn{1}{c}{} \\
\cline { 1 - 3 }+ & - & - & Seronegative \\
+ & - & - & Early phase of acute infection or non-specificity \\
+ & + & - & Acute infection \\
+ & + & + & Acute infection (late phase) or reactivation \\
- & + & + & Previous infection \\
- & + & - & Acute or previous infection \\
- & - & + & Previous infection or non-specificity \\
\hline
\end{tabular}

EBNA: Epstein-Barr virus nuclear antigen, VCA: viral capsid antigen,

${ }^{\text {a }}$ Further analyses required. 
Table II. Laboratory Findings of Patients Hospitalized with Acute Epstein-Barr Virus (EBV) Infection.

\begin{tabular}{lcccc}
\hline Laboratory values & $\mathrm{N}$ & Median & Minimum & Maximum \\
\hline Hemoglobin, g/dl & 66 & $11.52 \pm 1.4^{*}$ & 8.3 & 15.1 \\
White blood cells, $/ \mathrm{mm}^{3}$ & 66 & 1,3625 & 5,800 & 48,100 \\
Granulocytes, $/ \mathrm{mm}^{3}$ & 66 & 3,310 & 830 & 44,100 \\
Lymphocytes, $/ \mathrm{mm}^{3}$ & 66 & 6,735 & 1,100 & 26,730 \\
Monocytes, $/ \mathrm{mm}^{3}$ & 66 & 700 & 20 & 8,600 \\
Eosinophils, $/ \mathrm{mm}^{3}$ & 66 & 25 & 0 & 900 \\
C-reactive protein, mg/dl & 66 & 1.1 & 0.1 & 83.0 \\
Erythrocyte sedimentation rate, mm/hour & 40 & 30.50 & 3 & 120 \\
Aspartate aminotransferase, IU/L & 66 & 45 & 18 & 508 \\
Alanine aminotransferase, IU/L & 66 & 40 & 7 & 717 \\
\hline
\end{tabular}

*: mean \pm standard deviation

were under 6 years old, including 23 (34.8\%) children below 3 years of age.

The most common symptom of the patients on admission was fever $(92.4 \%)$. Other frequent symptoms were as follows: sore throat $(43.9 \%)$, neck swelling $(63.6 \%)$, rash $(24.2 \%)$, respiratory distress $(13.6 \%)$, nausea-vomiting $(12.1 \%)$, fatigue $(7.6 \%)$, abdominal pain $(7.6 \%)$ and headache $(3.0 \%)$. The median duration of fever was 6 days (minimum 2 days-maximum 80 days). On physical examination, there was exudative membranous tonsillopharyngitis in 48 patients $(72.7 \%)$, tonsillopharyngitis without exudative membranes in 8 patients $(12.1 \%)$ and cervical lymphadenopathy in 54 patients $(81.8 \%)$. Hepatomegaly and splenomegaly were investigated by both physical examination and ultrasound imaging, and present in 20 patients $(30.3 \%)$ and 28 patients $(42.4 \%)$, respectively.

Increased white blood cell count was observed in $43(65.1 \%)$ of the patients. None of the patients had low leukocyte count. Lymphocytosis was present in 28 patients $(42.4 \%)$. There were 38 patients $(57.5 \%)$ whose lymphocyte/leukocyte ratio was above $50 \%$. High level of C-reactive protein (CRP) was present in $27(40.9 \%)$ of the patients. Twenty-seven patients $(40.9 \%)$ had elevated liver transaminase levels. On peripheral blood smear evaluation, there were isolated reactive lymphocytes in 36 (54.5\%), reactive lymphocytes along with Downey cells in $13(19.7 \%)$, and isolated Downey cells in $2(3.0 \%)$ of the patients. Laboratory values of the patients are reviewed in Table II.

Both EBV VCA IgM and EBV VCA IgG were positive in $51(77.2 \%)$ of the patients. Ten patients $(15.1 \%)$ presented with isolated EBV VCA IgG positivity and 5 patients $(7.5 \%)$ had isolated EBV VCA IgM positivity.

Fifty-three $(80.3 \%)$ of our patients had visited a doctor at least once during the week before hospitalization; and the ratio of patients using antibiotics was $77.3 \%$ on admission. Skin rash occurrence was observed in $14(27.4 \%)$ of the patients who used antibiotic treatment and in $2(13.3 \%)$ patients who did not; but there was no significant difference between two groups $(\mathrm{p}>0.05)$.

\section{Discussion}

EBV-associated IM is more common in adolescents and adults, whereas younger children mostly have mild disease course or asymptomatic primary EBV infection. ${ }^{8}$ Unexpectedly, $51.5 \%$ of our patients were under 6 years of age; and the ratio of the patients who were 3 years old or younger was $22.7 \%$. Similar to our finding, Sumaya and Ench $^{9}$ reported that $41 \%$ of children with acute EBV infection were aged 4 years and below; the ratio was $40 \%$ in another study by Topp et al. ${ }^{10}$ as well. All these findings are 
contrary to the classical knowledge about the low frequency of symptomatic EBV infection in this age group. This might be related to underdiagnosing EBV in younger children, because they have usually vague physical symptoms or decreased heterophile antibody response causing false negative results. ${ }^{8,11,12}$ Additionally, Henke et al. ${ }^{13}$ showed that the rate of hospitalization due to EBV infection was higher $(25 \%)$ in young children. Since the present study reviewed hospitalized children and all the patients had been tested for specific EBV antibody responses, the ratio of younger aged patients might have been found higher.

The most common physical findings in our study were fever, exudative membranous tonsillopharyngitis and cervical lymphadenopathy. Rash was detected in $24.2 \%$ of the patients. Erythematous maculopapular rash associated with acute EBV infection has been reported in the literature at varying rates, between $4 \%$ and $13 \% .{ }^{14}$ In addition, with an unknown mechanism following amoxicillin or ampicillin use, hypersensitivity reaction may develop and skin rash may occur. ${ }^{15}$ In our study $77.3 \%$ of the patients had been under antibiotic treatment prior to admission, however there was no statistically significant difference between the rash occurrence ratios of the patients who had received antibiotic treatment and those who had not.

In this study, the presence of hepatomegaly and splenomegaly were assessed by both physical examination and ultrasound, and found at $30.3 \%$ and $72.4 \%$, respectively. These ratios were relatively higher compared to the literature. ${ }^{10,16}$ However, Dommerby et al. ${ }^{17}$ reported that among the patients with hepatomegaly and splenomegaly confirmed with imaging, only about $1 / 5$ of them were detected on physical examination. Therefore, it may be more appropriate to evaluate the presence of hepatosplenomegaly by ultrasonography in addition to physical examination when EBV infection is suspected. ${ }^{10}$

Leukocytosis and lymphocytosis are the most frequentEBV associated laboratory findings. ${ }^{10,18}$ There are some studies indicating elevated lymphocyte count is more specific to EBV infection, and recommend using lymhocyte/ leucocyte ratio in the diagnosis. ${ }^{19,20}$ In addition to this, atypical lymphocytes, also called Downey cells, can be detected in peripheral blood smear beginning from the second week of EBV infection. ${ }^{5}$ Although these cells are not specific for EBV, they support the diagnosis. ${ }^{21}$ Brigden et al. ${ }^{22}$ showed increased lymphocyte/ leukocyte ratio $(>50 \%)$ in two-thirds and atypical lymphocyte presence in $75 \%$ of their patients. In our study, $65.1 \%$ of the patients had leukocytosis, $42.4 \%$ had lymphocytosis and $57.5 \%$ had lymphocyte/leukocyte ratio $>50 \%$. Reactive lymphocytosis, atypical lymphocytes or both were present in $77.2 \%$ of the peripheral blood smear of the patients. However, leukocytosis and lymphocytosis may not be present in all cases. ${ }^{23}$ Even though leukocyte and lymphocyte counts are in normal range, EBV should be considered in a patient with consistent clinical findings; especially when the lymphocyte/leukocyte count ratio is increased and there are reactive or atypical lymphocytes on peripheral blood smear. Thus it is important to perform peripheral blood smear evaluation in all patients in order to detect atypical lymphocytes and also distinguish them from blasts. ${ }^{22}$

Monospot testing based on the heterophile antibody response is not recommended because of the high rates of false negative or false positive results in the pediatric age group. ${ }^{10}$ Evaluation of EBV-specific antibodies (EBV VCA IgM, IgG and EBNA-1 IgG) and EBV DNA confirms the EBV diagnosis in most patients. ${ }^{10}$ Classical information indicates that the presence of VCA IgG and VCA IgM in the absence of EBNA IgG shows acute infection; and the presence of VCA IgG and EBNA IgG in the absence of VCA IgM shows past infection. ${ }^{24}$ Isolated elevation of EBV VCA IgM or VCA IgG may be seen in acute EBV infection as well. ${ }^{24}$ In our study EBNA IgG was negative in all patients; positive EBV VCA IgM and IgG levels were detected in 51 patients in accordance with the classical antibody responses of acute EBV infection. Isolated elevation of EBV VCA IgM and VCA IgG were detected in 5 and 10 of our patients, respectively. Unfortunately, EBV serology was not repeated in these patients for further assessment of their immune response.

According to their recent medical histories on admission, it was found that $80.3 \%$ of our patients had seen a doctor at least once 
during the week before hospitalization; and the ratio of the patients using antibiotics was $77.3 \%$. Neither rapid streptococcal antigen test nor throat culture had been performed in these patients to support the diagnosis of Group A beta-hemolytic streptococcal tonsillopharyngitis. Immune suppression due to viral infection can lead to development of other diseases. In fact, Group A beta-haemolytic streptococcus is the most frequently seen pathogen concurrent with EBV infection. It is also reported that $20 \%$ of healthy children are carriers of beta hemolytic streptococci; so it should be kept in mind that it can be detected incidentally during EBV infection as well. ${ }^{10,25}$ Performing rapid streptococcal antigen test and throat culture for differential diagnosis of tonsillitis may be effective in both facilitating the diagnosis and reducing antibiotic consumption in these patients.

There is a broad spectrum of complications due to EBV infection. The most serious acute complications are splenic rupture and upper airway obstruction, estimated at $0.1-0.5 \%$ and $1-3.5 \%$ of IM cases, respectively. ${ }^{7}$ Only mild upper airway obstruction had developed in $13.6 \%$ of our patients, and all of them recovered in a very short time without any intervention. Long term complications as allergy, autoimmunity and malignancies may be seen associated with EBV. ${ }^{7}$ Unfortunately, we had no long term follow up data of our patients.

Our study had some limitations due to its retrospective design. Only a selected group of hospitalized acute EBV cases were evaluated, thus it is likely that the study included younger children with serious clinical condition and did not cover the patient population who had milder EBV associated disease not requiring hospitalization. Secondly, we had no data available for longer follow-up to have an opinion about the long term complications of EBV.

The present study demonstrates that acute EBV infection resulting in admission to hospital is common in younger children, even in preschool period. Serological tests for EBV specific antibody responses and peripheral blood smear evaluation are important diagnostic tools. In addition, rapid streptococcal antigen test and throat culture should be performed in patients presenting with tonsillopharyngitis in order to exclude Group A beta-hemolytic streptococci and reduce unnecessary antibiotic consumption.

\section{REFERENCES}

1. Balfour HH Jr, Sifakis F, Sliman JA, Knight JA, Schmeling DO, Thomas W. Age-specific prevalence of Epstein-Barr virus infection among individuals aged 6-19 years in the United States and factors affecting its acquisition. J Infect Dis 2013; 208: 1286-1293.

2. Hjalgrim H, Friborg J, Melbye M. The epidemiology of EBV and its association with malignant disease. In: Arvin A, Campadelli-Fiume G, Mocarski E, Moore PS, Roizman B, Whitley R, Yamanishi K (eds). Human Herpesviruses: Biology, Therapy, and Immunoprophylaxis. Cambridge: Cambridge University Press, 2007.

3. Dunmire SK, Grimm JM, Schmeling DO, Balfour $\mathrm{HH}$ Jr, Hogquist KA. The incubation period of primary Epstein-Barr virus infection: Viral dynamics and immunologic events. PLoS Pathog 2015; 11; e1005286.

4. Balfour HH Jr, Holman CJ, Hokanson KM, et al. A prospective clinical study of Epstein-Barr virus and host interactions during acute infectious mononucleosis. J Infect Dis 2005; 192: 1505-1512.

5. Balfour HH Jr, Dunmire SK, Hogquist KA. Infectious mononucleosis. Clin Transl Immunology 2015; 4: e33.

6. Grose C. The many faces of infectious mononucleosis: The spectrum of Epstein-Barr virus infection in children. Pediatr Rev 1985; 7: 35-44.

7. Bolis V, Karadedos C, Chiotis I, Chaliasos N, Tsabouri S. Atypical manifestations of Epstein-Barr virus in children: Adiagnostic challenge. J Pediatr (Rio J) 2016; 92: 113-121.

8. Sumaya CV. Primary Epstein-Barr virus infections in children. Pediatrics 1977; 59: 16-21.

9. Sumaya CV, Ench Y. Epstein-Barr virus infectious mononucleosis in children. I. Clinical and general laboratory findings. Pediatrics 1985; 75: 1003-1010.

10. Topp SK, Rosenfeldt V, Vestergaard H, Christiansen $\mathrm{CB}$, Von Linstow ML. Clinical characteristics and laboratory findings in Danish children hospitalized with primary Epstein-Barr virus infection. Infect Dis (Lond) 2015; 47: 908-914.

11. Tamir D, Benderly A, Levy J, Ben-Porath E, Vonsover A. Infectious mononucleosis and Epstein-Barr virus in childhood. Pediatrics 1974; 53: 330-335. 
12. Sumaya CV, Ench Y. Epstein-Barr virus infectious mononucleosis in children. II. Heterophil antibody and viral-specific responses. Pediatrics 1985; 75: 1011-1019.

13. Henke CE, Kurland LT, Elveback LR. Infectious mononucleosis in Rochester, Minnesota, 1950 through 1969. Am J Epidemiol 1973; 98: 483-490.

14. Thompson DF, Ramos CL. Antibiotic-induced rash in patients with infectious mononucleosis. Ann Pharmacother 2017; 51: 154-162.

15. Jappe U. Amoxicillin-induced exanthema in patients with infectious mononucleosis: Allergy or transient immunostimulation? Allergy 2017; 62: 1474-1475.

16. Kofteridis DP, Koulentaki M, Valachis A, et al. Epstein Barr virus hepatitis. Eur J Intern Med 2011; 22: 7376.

17. Dommerby H, Stangerup SE, Stangerup M, Hancke S. Hepatosplenomegaly in infectious mononucleosis, assessed by ultrasonic scanning. J Laryngol Otol 1986; 100: 573-579.

18. Gao LW, Xie ZD, Liu YY, Wang Y, Shen KL. Epidemiologic and clinical characteristics of infectious mononucleosis associated with EpsteinBarr virus infection in children in Beijing, China. World J Pediatr 2011; 7: 45-49.

19. Wolf DM, Friedrichs I, Toma AG. Lymphocyte-white blood cell count ratio: A quickly available screening tool to differentiate acute purulent tonsillitis from glandular fever. Arch Otolaryngol Head Neck Surg 2007; 133: 61-64.
20. Lennon P, O'Neill JP, Fenton JE, O'Dwyer T. Challenging the use of the lymphocyte to white cell count ratio in the diagnosis of infectious mononucleosis by analysis of a large cohort of Monospot test results. Clin Otolaryngol 2010; 35: 397-401.

21. Auwaerter PG. Infectious mononucleosis in middle age. JAMA 1999; 281: 454-459.

22. Brigden ML, Au S, Thompson S, Brigden S, Doyle $\mathrm{P}$, Tsaparas Y. Infectious mononucleosis in an outpatient population: Diagnostic utility of 2 automated hematology analyzers and the sensitivity and specificity of Hoagland's criteria in heterophilepositive patients. Arch Pathol Lab Med 1999; 123: 875-881.

23. Ventura KC, Hudnall SD. Hematologic differences in heterophile-positive and heterophile-negative infectious mononucleosis. Am J Hematol 2004; 76: 315-318.

24. De Paschale M, Clerici P. Serological diagnosis of Epstein-Barr virus infection: Problems and solutions. World J Virol 2012; 1: 31-43.

25. Ueda S, Uchiyama S, Azzi T, et al. Oropharyngeal group A streptococcal colonization disrupts latent Epstein-Barr virus infection. J Infect Dis 2014; 209: 255-264. 